Ethiopian Journal of Environmental Studies \& Management 10(2): 186 - 191, 2017.

ISSN:1998-0507

doi: http://dx.doi.org/10.4314/ejesm.v10i2.5

Submitted: October 02, 2016

Accepted: March 06, 2017

\title{
EFFICIENT HEALTH CARE SERVICE DELIVERY USING NETWORK ANALYSIS: A CASE STUDY OF KWARA STATE, NIGERIA
}

\author{
OYELERE, B.A., ${ }^{1}$ RAJI, S.A., ${ }^{2}$ *OYEYEMI, G.M., ${ }^{3}$ SALAMI, A.0. ${ }^{4}$ AND BELLO, F.W. ${ }^{3}$ \\ ${ }^{1}$ Ladoke Akintola University of Technology Ogbomosho, Oyo State, Nigeria \\ ${ }^{2}$ Federal Polytechnic Offa, Kwara State, Nigeria \\ ${ }^{3}$ University of Ilorin, Ilorin, Kwara State, Nigeria \\ ${ }^{4}$ University of Agriculture, Abeokuta, Ogun State, Nigeria
}

\begin{abstract}
This paper addresses challenges with prompt health care delivery using Network Analysis of Critical Path Model (CPM) to plan the hospital capacity with a view to achieving prompt health care service delivery. Hospital activities were identified as either critical and non critical, time or cost consideration was factored in. In all, 16 state health institutions were purposively selected on the basis of most equipped from 55 state health institutions. Data on patients' arrival and departure were observed and recorded for a period of six months. This was subjected to further analysis to identify the most important activities (critical path) and less important together with their time duration. The average total time spent in the hospital was 43 minutes but with effective capacity planning using network analysis the total time was reduced to 18 minutes and the critical path (activities) were identified to be: A - Card section, F-Medical Doctor and H-Medical Team.
\end{abstract}

Key Words: Critical Path Model (CPM), Capacity Planning (CP), Hospital Services, Network Analysis

\section{Introduction}

The challenges facing the health care sector is that of unimpeded access to health care service. These challenges stem from inadequacies in equipment and manpower which often lead to prolonged and stressful waiting time for patients to access health care services. Waiting lines or queues occurs in a variety of situations when customers' or patients arriving for service must queue before they can be served or attended to. However, no one likes a waiting situation because people highly value their time and waiting is essentially a non-value added activity. In health care service delivery, waiting is equally encountered as, Lawrence and Pasternack (2004) posit that even when we have a confirmed appointment with a doctor, we frequently wait for medical treatment. Equally, Oshotimehin (2009) reported that the challenges in the health sector are that, most people over the years have lost faith in the health system, he therefore encouraged Nigerians to patronize the hospitals, that government is doing everything within its power to equip the hospitals and equally work on patients waiting time, which is a major concern in health care service delivery. 
Saulnier et al. (2004) equally buttressed the above view that, excessive waiting for health care service can result in significant health and economic impacts, such as poor post operative outcome e.g. death, increase in health expenditure before and after treatment, increased prescription cost to manage the condition during wait, loss of personal income and increase public expenditure on income support and loss in societal capacity.

Management of our health institutions are very much aware of queuing up problems and no concerted effort is paid to the problem due to lack of technical know-how to tackle the problem and reluctance to spend money and time to address this all important problem.

Experts have therefore traced this development to deficiency in capacity planning which is essential in healthcare service delivery because the physical facilities layout in most health institutions is grossly inadequate and has made easy access to healthcare service very difficult for the patients.

To address this serious problem of queuing, there are many quantitative tools, models and theories that can be employed to proffer solution to these practical and operational problems in our business environment. These techniques include; Linear and dynamic Programming, Inventory Models, Markov Analysis, Simulation and Queuing Theory and Network and Critical Path Analysis, among others.

This study therefore assesses the use of network and critical path method to plan capacity in health care service delivery with a view to achieving patient's satisfaction by improving on waiting time in health institutions.

\section{Statement of the Problem}

Queues are observed in everyday life order to bring orderliness into the society in which we live. Queue problem are observed in so many places including banks, bus stop, filling stations, post office, hospitals and so on.

Most queuing system exhibit the features of the customers having to wait for their turn in order to be served or a state in which the servers are idle, waiting for the customers to arrive for service, both type of waiting attract cost. When the waiting lines for service consist of in animate objects (e.g. Materials component or parts) waiting for some sorts of processing (e.g. on a machine), waiting line is primarily an economic problem such as deciding how long the line should be and how many machines should be purchased. That, when, however waiting in line are people waiting for a service such as health care services, then the problem, in addition to an economic one, has psychological elements such as frustration, loss of goodwill, loss of personal income etc.

The main problem that comes to light especially for health care services delivery is how to bridge the gap between waiting and service to ensure efficient health care service delivery.

\section{Methodology \\ Capacity Planning Using Network and Critical Path Analysis}

The concept of capacity planning is a key concept in this study. This is because the focus of the study is to assess how capacity planning can enhance health care service delivery using critical path method of Network analysis. Campbell (2007) describes planning as involving a system of making decisions about how an organisation will use its resources in the 
future. In fact planning is often refer to as the primary management function because it establishes the basis for all other things managers do as they organize, lead and control. Capacity planning on the other hand was described as the process of determining the production capacity needed by an organisation to meet changing demand for its product. Mechandirata (2011) reported that in health care Capacity Planning, it is common for health care managers to project work load for physical infrastructure and manpower planning. That such Capacity Planning may be done at different level for instance, department, hospital or even national levels. Management study guide describes capacity planning as an essential tool in determining the optimum production capacity and its plays an important role in decision making process. Network analysis plays an important role in project management and planning (Vohra, 2007; Srivastava et al., 2002). One of the tools use to plan capacity is Network analysis (Taha, 2007). Lawrence and Pasternack (2004) reported that the use of network models in capacity planning provides both a convenient way of expressing the situation pictorially and efficient mechanism for finding optimal solution with minimal input.

\section{Model Specification}

The model used in this study is Critical Path Model (CPM) of network analysis. The model fit perfectly into the subject under consideration. Preliminary survey of the health institutions in Kwara State confirms the suitability of the Critical Path Model (CPM). Capacity building analysis when constructed which at a glance gives the planning and non- planning attributes in hospital services management.

The activities which are critical and non-critical were identified and cost consideration was factored in. the result is with effective planning such that the time spent by the patient in the hospital system can be minimized. The ultimate aim is the reduction in patient waiting time.

Critical path analysis is one of the techniques used in project management. The main objective of project management is to minimize the total project time subject to the resource constraint. Therefore, treatment of patient as a whole project can be delineated into various activities or steps. The diagram in Figure 1 depicts the network activities of typical hospital activities especially for our patients' facilities which are the focus of this study.

\section{Assumption of Network Model}

For network model to be capable of been applicable to capacity planning in health care institutions,

$\checkmark$ The project team`s ability to reasonably predict the scope, schedule and cost of the project is not in doubt.

$\checkmark$ The whole project can be broken down into series of identifiable tasks.

$\checkmark$ Each task is assigned a starting date/time duration and end date/time.

The staff will always be able to complete the required task by knowledge and expertise in the field.

\section{Data Collection and Analysis}

The state owned health institutions are fifty five in number out of which sixteen (16) hospitals where purposively selected on the basis of most equipped. The sixteen hospitals selected cut across the three health care levels of primary, secondary and tertiary health care service 
Efficient Health Care Service Delivery Using Network Analysis................. OYELERE et al.

delivery that spread across the sixteen Local Government areas in Kwara state.

Data on Patients arrival and departure into the hospitals were observed and recorded for a period of six months and further analyzed as depicted in table 1 .

Table 1: Mean Arrival Rate and Service Rate for Patients of Selected State Health Institutions in Kwara State

\begin{tabular}{llcccc}
\hline S/N & HOSPITALS & $\begin{array}{l}\text { NO OF } \\
\text { SERVER }\end{array}$ & $\begin{array}{l}\text { MEAN } \\
\text { ARRIVAL } \\
\text { RATE PER } \\
\text { DAY } \lambda\end{array}$ & $\begin{array}{l}\text { MEAN } \\
\text { DEPATURE } \\
\text { RATE PER } \\
\text { DAY } \mu\end{array}$ & $\begin{array}{l}\text { REMARK } \\
>\text { Greater than }\end{array}$ \\
\hline 1. & AFON & 1 & 32 & 16 & $\lambda>\mu$ \\
2. & BARUTEN & 1 & 28 & 12 & $\lambda>\mu$ \\
3. & EDU & 1 & 30 & 26 & $\lambda>\mu$ \\
4. & EKITI & 1 & 16 & 11 & $\lambda>\mu$ \\
5. & IFELODUN & 1 & 27 & 11 & $\lambda>\mu$ \\
6. & ILORIN EAST & 4 & 18 & 13 & $\lambda>\mu$ \\
7. & ILORIN WEST & 2 & 14 & 11 & $\lambda>\mu$ \\
8. & ILORIN SOUTH & 3 & 13 & 12 & $\lambda>\mu$ \\
9. & OMU - ARAN & 1 & 9 & 7 & $\lambda>\mu$ \\
10. & ISIN & 1 & 28 & 12 & $\lambda>\mu$ \\
11. & KAIAMA & 1 & 11 & 6 & $\lambda>\mu$ \\
12. & MORO & 1 & 30 & 21 & $\lambda>\mu$ \\
13. & OFFA & 4 & 21 & 13 & $\lambda>\mu$ \\
14. & OKE- ERO 1 & 1 & 10 & 5 & $\lambda>\mu$ \\
15. & OYUN 1 & 1 & 9 & 4 & $\lambda>\mu$ \\
16. & PATEGI 1 & 1 & 31 & 21 & $\lambda>\mu$ \\
\hline
\end{tabular}

For all the selected sixteen health institutions studied, the arrival rate is greater than the service delivery rate, $\lambda>\mu$ meaning that queue is imminent in all the studied hospitals. (Table 1)

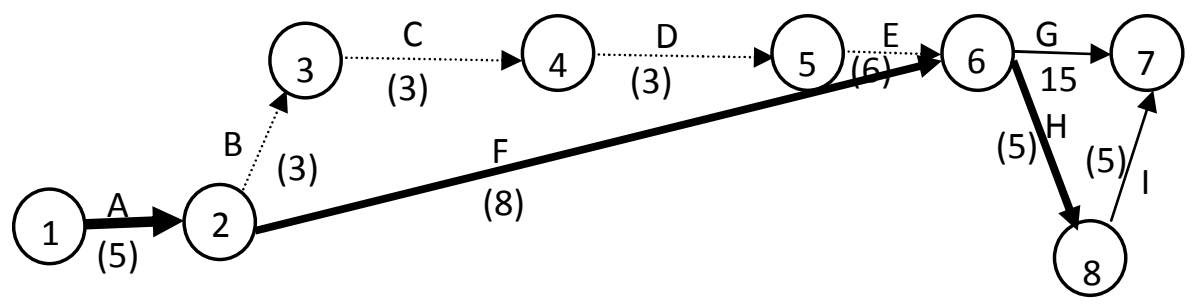

Figure 1: Network Diagram of Hospital Activities 
Interpretation:

Thick line represents the main or critical activities

Single line represents the minor activities Broken line represents the idle or noncritical activities

Number in bracket against each activity represents the duration in minutes

The activities, which consume time and resources (Personnel, Machine, Office space, Utilities etc.) are represented by arrow. The precedence relationships of the activities are indicated through the events (nodes). Therefore, events are represented by circles, they do not consume any resources but they signify the beginning and/or the ending of activities.

Table 2: The Hospital activities and The Critical Path Analysis

\begin{tabular}{|c|c|c|c|c|c|c|c|}
\hline Activities & Name & Duration (D) & $\mathrm{TE}_{\mathrm{j}}$ & $\mathrm{IE}_{\mathrm{i}}$ & $\mathrm{TE}_{\mathrm{j}}$ & $\mathrm{IE}_{\mathrm{i}-} \mathrm{TE}_{\mathrm{j}-\mathrm{D}}$ & Critical \\
\hline $\mathrm{A}(1,2)$ & Card Section & 5 & 0 & 5 & 5 & $5-0-5=0$ & Yes \\
\hline $\mathrm{B}(2,3)$ & $\begin{array}{l}\text { Blood Pressure } \\
\text { Check }\end{array}$ & 3 & 5 & 12 & 5 & $12-5-3=4$ & No \\
\hline $\mathrm{C}(3,4)$ & $\begin{array}{l}\text { Temperature } \\
\text { Check }\end{array}$ & 3 & 8 & 17 & 6 & $17-8-3=6$ & No \\
\hline $\mathrm{D}(4,5)$ & Pulse Check/etc & 3 & 11 & 20 & 9 & $20-11-3=6$ & No \\
\hline$E(5,6)$ & See Doctor & 6 & 17 & 25 & 12 & $25-17-6=2$ & No \\
\hline$F(2,6)$ & See Doctor & 8 & 13 & 21 & 15 & $21-13-8=0$ & Yes \\
\hline $\mathrm{G}(6,8)$ & $\begin{array}{l}\text { Lab. Testing/X- } \\
\text { ray etc. }\end{array}$ & 15 & 22 & 40 & 23 & $40-22-15=3$ & No \\
\hline $\mathrm{H}(6,9)$ & $\begin{array}{l}\text { Medical Team } \\
\text { Nurses etc }\end{array}$ & 5 & 22 & 27 & 38 & $27-22-5=0$ & Yes \\
\hline $\mathrm{I}(8,9)$ & $\begin{array}{l}\text { Medical Team } \\
\text { (Nurses) }\end{array}$ & 5 & 38 & 38 & 38 & $38-38-5=-5$ & No \\
\hline
\end{tabular}

\section{The Determination of Critical Path}

Table 2 gives the tabular presentation of the Network diagram of the activities. The time used also known as Duration, are the overall average spent by the patients in each step/activity base on the data collected which is presented in the third column.

Using both the forward pass and backward pass approach, the last column in the table indicates the most important activities (Critical Path) and these path (activities) are $\mathrm{A}(1,2)$ with duration of 5 minutes, $F(2,6)$ with duration of 8 minutes and $\mathrm{H}(6,9)$ with duration of 5 minutes. Therefore, the most important (critical path) in the Network of activities are $\mathrm{A}, \mathrm{F}$ and $\mathrm{H}$ with total duration of 18 minutes.

The result shows that for a patient to minimize time spent in the hospital, the three (3) activities namely; sorting card, consult doctor and see medical team are the critical activities that should be focused on in our hospitals to ensure that the waiting time or queue time is minimized to the barest minimum and ensure efficient healthcare service delivery.

Figure 1 above and Table 1 on hospital activities and the critical path analysis, shows that $\mathrm{A}, \mathrm{F}$ and $\mathrm{H}$ are critical to minimizing the patient waiting time in hospital, therefore, no waiting time cost is incurred and adequate 
medical attention was received. The above has shown that with effective capacity planning, cost of rendering health care service can be reduced tremendously.

\section{Discussion of Results and Conclusions}

The critical path method identified activities $\mathrm{A}, \mathrm{F}$ and $\mathrm{H}$ as the most critical or essential hospital activities that minimize the total time patient spent in the hospital system. The total time spent in the hospital before capacity planning was 43 minutes but with effective capacity planning the total time has been reduced to 18 minutes. This method also resulted in minimal total cost of health care service delivery; waiting cost was reduced to zero thereby reducing the total cost of health care service. Therefore, with effective planning using critical path (activities) model, time spent in hospital system by patient and total cost of health care service delivery are minimized.

\section{References}

Campbell, C. (2007). Introduction to Health Management, Essentials of Health Management, Planning and Policy. Unilag Press, Lagos, Pp. 97105.

Lawrence, J.A. Jr. and Pasternack, B.A. (2004). Applied Management Science. Modeling, Spread Sheet Analysis and Communication for Decision Making John Willey \& Sons, Inc.

Mamman A.B., Oyebanji, J.O. and Pretters, S.W (2000). Nigeria
People United, A future Assured. Vol.2, A Survey of State Gabumo Publications, Calabar, Nigeria.

Olujide, J.O. and Badmus, A.L. (1998). "Enhancing Patient Satisfaction Through Adequate Medical Care" Published by National Collaboration Centre for Education and Training in Health Planning and Management, Faculty of Business and Social Sciences University of Ilorin, Ilorin. Edited by Dr. A.O. Petu. Pp. 64-84.

Oshotimehin, A. (2009). Health Care Challenges, Health Column, the Nation, Vintage Press Ltd, Lagos, January 5, Pp. 22 - 31. Planning and Policy. Unilag Press, Lagos, Pp. 97105.

Saulnier, O., Shortt, M. and Gruenwoldt, M. (2004). The Taming of the Queue: towards a Cure for Health Care Wait Times. Discussion Paper, Canadian Medical Association. Vol. 2. Pp.11-15.

Srivastava, U.K., Shenoy, G.V. and Sharma, S.C. (2002). Quantitative Techniques for Managerial Decisions, New Age International Publisher Ltd, New Delhi, Pp.25.

Taha, H.A. (2007). Operations Research: An introduction, Pearson Prentice Hall. Upper Saddle River. N.J. 07458.

Vohra, N.D (2007). Quantitative Techniques in Management. 3rd Edition Tata McGraw-Hill Publishing Company Ltd. 